\title{
Synthesis and Characterization of Polyurethanes from Residual Palm Oil with High Poly-Unsaturated Fatty Acid Oils as Additive
}

\author{
Javier Chavarro Gomez ${ }^{1}$ (D), Rabitah Zakaria ${ }^{1, *}$, Min Min Aung ${ }^{2}\left(\mathbb{D}\right.$, Mohd Noriznan Mokhtar $^{1}$ (D) \\ and Robiah Yunus ${ }^{3}$
}

1 Department of Process and Food Engineering, Faculty of Engineering, Universiti Putra Malaysia, UPM, Serdang 43400, Selangor, Malaysia; chagoja@hotmail.com (J.C.G.); noriznan@upm.edu.my (M.N.M.)

2 Institute of Tropical Forestry and Forest Products, University Putra Malaysia, UPM, Serdang 43400, Selangor, Malaysia; minmin_aung@upm.edu.my

3 Department of Chemical and Environmental Engineering, Faculty of Engineering, Universiti Putra Malaysia, UPM, Serdang 43400, Selangor, Malaysia; robiah@upm.edu.my

* Correspondence: rabitah@upm.edu.my; Tel.: +60-3-89464301; Fax: +60-3-89464440

check for updates

Citation: Gomez, J.C.; Zakaria, R.; Aung, M.M.; Mokhtar, M.N.; Yunus, R. Synthesis and Characterization of Polyurethanes from Residual Palm Oil with High Poly-Unsaturated Fatty Acid Oils as Additive. Polymers 2021, 13, 4214. https://doi.org/10.3390/ polym13234214

Academic Editors: Andrzej Puszka and Beata Podkościelna

Received: 29 September 2021

Accepted: 19 November 2021

Published: 1 December 2021

Publisher's Note: MDPI stays neutral with regard to jurisdictional claims in published maps and institutional affiliations.

Copyright: (c) 2021 by the authors. Licensee MDPI, Basel, Switzerland. This article is an open access article distributed under the terms and conditions of the Creative Commons Attribution (CC BY) license (https:// creativecommons.org/licenses/by/ $4.0 /)$.

\begin{abstract}
In the effort to produce renewable and biodegradable polymers, more studies are being undertaken to explore environmentally friendly sources to replace petroleum-based sources. The oil palm industry is not only the biggest vegetable-oil producer from crops but also one the biggest producers of residual oil that cannot be used for edible purposes due to its low quality. In this paper the development of biopolymers from residual palm oil, residual palm oil with $10 \%$ jatropha oil, and residual palm oil with $10 \%$ algae oil as additives were explored. Polyols from the different oils were prepared by epoxydation with peroxyacetic acid and alcoholysis under the same conditions and further reacted with poly isocyanate to form polyurethanes. Epoxidized oils, polyols and polyurethanes were analyzed by different techniques such as TGA, DSC, DMA, FTIR and H-NMR. Overall, although the IV of algae oil is slightly higher than that of jatropha oil, the usage of algae oil as additive into the residual palm oil was shown to significantly increase the hard segments and thermal stability of the bio polyurethane compared to the polymer with jatropha oil. Furthermore, when algae oil was mixed with the residual palm oil, it was possible to identify phosphate groups in the polyol which might enhance the fire-retardant properties of the final biopolymer.
\end{abstract}

Keywords: bio-based polyurethanes; jatropha oil; algae oil; recovered palm oil

\section{Introduction}

Each year around the world, a large amount of polyurethanes (PU) are produced with a wide range of applications. Polyurethanes are highly versatile materials and can be used for multiple purposes such as molding, foaming, packaging, elastomers, coating, insulating, sealing etc. causing demand for them to continuously increase. In 2020, it was reported that 24 million tons of polyurethanes (PU) were produced [1], with most of it from petroleum-based feedstock [2,3]. Unfortunately, the instability in the cost of petroleum, and the non-renewability and the non-biodegradability of these polymers, have urged researchers to find other environmentally friendly alternatives.

In the past few years, several researchers have turned back their attention to the development of biopolyurethane from vegetable oils due to straightforward processing, biodegradability and renewability of the raw material. For example, drying oils such as linseed oil [4] showed great performance for the production of biopolyurethane especially for paint coating applications due to effortless epoxidation. Semi-dry oils such as soy bean [5] and sunflower [3] was shown to produce polyurethane with similar characteristics to petroleum-based rigid PU and non-drying oils such as cottonseed oil [6], castor oil [7] and refined palm oil [8] have been used for the development of foams and elastomers by 
different polymerization methods with the inclusion of additives. Unfortunately, the high cost of vegetable oils (especially from dry and semi-dry oils) and the competition with edible purposes limit their full implementation.

Despite this, other sources of vegetable oils with less competition for food supply can be explored as raw materials for the development of bio-polymers. In Malaysia, the extraction of crude palm oil (CPO) from Elaeis guineensis produces massive amounts of by-products in the form of palm pressed fiber, empty fruit bunch (EFB), palm oil mill effluent (POME), etc. which are disposed of with a high amount of oil still within. As an example, 1.13 tons of EFB was produced per 1 ton of crude palm oil (CPO) in 2012 [9] with $3-12 \%$ of CPO remaining on the OPEFB [10]. The residual palm oil (RPO) showed similar fatty acid composition to $\mathrm{CPO}$ but with lower oil quality due to the formation of degradation products such as free fatty acids (FFA), peroxides, etc. [11]. Therefore, with an annual production of some 19.14 million tons of crude palm oil in 2020 [12], the EFB itself can yield about 2.5 million tons of residual oil if fully recovered. Since this residual oil is not fit for consumption due to the degradation products, its utilization to other non-food products such as bio-polyurethane has potential economic and environmental benefits.

Nevertheless, the low degree of unsaturation in RPO impede the direct usage of this material for the development of polymers. To achieve a good degree of polymerization, the vegetable oil requires a high degree of unsaturation which is measured by the iodine absorption per $100 \mathrm{~g}$ of oil, and this value is named iodine value (IV). The functionality and the degree of unsaturation of the resulting polyol are linked and showed to have a significant effect on the mechanical properties and stability of the resulting polymer [2]. Polyols with low functionality and high molecular weight such as from palm oil (functionality of 1.7) produce soft and more fragile polymers due to relatively lesser crosslinking in the polymeric matrix [13]. This limits it uses and hampers its full implementation. Several studies have been undertaken on converting palm oil to polyol and polyurethane using technique such as epoxidation [14,15], transesterification [16] and polycondensation [17]. However, in all these studies the final polyurethane is a mixture between petrochemical polyol and palm oil polyol which is required in order to achieve the desired strength and thermal properties. This will ultimately affect the biodegradation properties of the final polymer. Tanaka et al. [18] produced rigid polyurethanes from palm oil by glycerolysis followed by hydrolysis. They converted the triglycerides (TG) in the crude palm oil into mono-glycerides using glycerol and alcohol at high temperature. This process showed to significantly increase the functionality of the polyol by adding two hydroxyl groups instead of the untreated CPO with functionality only in the fatty acid chains in the first/second or first/third position of the TG. The final polyurethane is produced by reacting the hydroxylated oil with polyethylene glycol (PEG) or diethylene glycol (DEG) and polyisocyanate (MDI). Hence, the addition of a significant amount of petrochemical compound (PEG/DEG) is needed to produce polyurethane with acceptable mechanical properties.

Cardeño et al. [13] compared the thermal stability of alkyd resins produced from refined, bleached and deodorized soy bean oil (RBD-SBO) and mixtures of RBD-SBOrecovered frying oils, palm oil and castor oil. Their research showed that the highest thermal stability was from the mixture RBD-SBO/castor oil (70/30) followed by RBDSBO/frying oil and RBD-SBO/palm oil. Therefore, palm oil with a low a degree of unsaturation can be blended with oils of a very high degree of unsaturation, ideally from non-food sources, to increase the functionality of the oil mix. jatropha oil and algae oil are suitable candidates for such purpose.

Jatropha oil is a non-edible, highly unsaturated oil mainly from C18:1 and C18:2 fatty acids and has been utilized for the development of biopolymers. Moreover, the oil from Jatropha curcas has been used for the production of polymeric adhesives not only because of the high unsaturation but also because of the high content of gums that can enhance adhesive properties [19]. Algae oil is another less explored renewable source that has shown potential to be used for the development of PU [20]. With the increasing usage of microalgae technology for the capture and reduction of $\mathrm{CO}_{2}$ emission, a huge amount of 
non-edible algae waste can be utilized for the production of biopolymers [21]. Algae oil contains a high degree of unsaturation (60-80\% unsaturated fatty acids) basically from palmitoleic fatty acids $(\sim 37 \%$, C16:1), oleic acid $(\sim 11.2 \%, C 18: 1)$ and linoleic acid $(\sim 40 \%$, C18:2) [22]. Also, algae oil contains long polyunsaturated carbon chains (C22:3, C25:3) that add variation to the length of elastically active network chains and dangling chains in the polymer network to produce polyurethanes foams with similar thermal properties to foams from commercial petroleum polyols [23]. Roesle et al. [24] showed that oil from the diatom Phaeodactylum tricornutum has diglyceride structure with phosphate end-groups which can significantly enhance the thermal characteristics of the final biopolymer. However, the composition of algae oil vastly differs between species and growth condition. This variation can greatly affect the final mechanical and thermal properties of the polyurethane.

Therefore, our research focuses on the development of biodegradable polyurethanes from residual palm oil (RPO) with two highly unsaturated vegetable oils such as algae oil (AO) from Chlorella vulgaris and jatropha oil (JO) from Jatropha curcas as additive to produce polyurethanes. To the best of our knowledge, there is very limited study in the literature that explore the development of PU from recovered oil from palm oil waste such as empty fruit bunch and POME sludge. Residual palm oil has a different fatty acid composition, mono and diglyceride and free fatty acid contents from refined palm oil which may result in different macromolecular configuration after polymerization. Hence, this study aims to develop PU from RPO and compared that to the PU of RPO mixed with JO and AO. Since both $\mathrm{JO}$ and $\mathrm{AO}$ are highly unsaturated oils with a similar degree of unsaturation but with different composition and fatty acid structure, its effect on the thermal characteristic of the resulting polyurethane is evaluated.

\section{Materials and Methods}

\subsection{Materials}

RPO was recovered from palm oil mill effluent (POME) collected from the last sludge pit at Felda Sungai Tengi Palm Oil Mill located in Perak, Malaysia. AO was manually extracted from the dry algae powder of the species Chlorella vulgaris purchased from Purebulk (Los Angeles, California, CA, USA). JO was provided by Biofuel Bionas Sdn Bhd, Kuala Lumpur, Malaysia. Formic acid 98\% was supplied by Friendemann Schimdt chemicals (Kuala Lumpur, Malaysia). Hydrogen peroxide $50 \%$ was purchased from R\&M Chemicals (Selangor, Malaysia). Other chemical such as methanol reagent, hydrogen bromide, chlorobenzene, acetone, potassium hydrogen phthalate, phthalic anhydride, pyridine, sodium hydroxide and potassium hydroxide were reagent grade chemicals, locally purchased and used as received.

\subsection{Oil Recovery}

RPO was recovered from POME by removing water and suspended solids using a centrifuge at $7000 \mathrm{rpm}$ (Centrifuge 5804, Enfield, CT, USA). The purified RPO was carefully collected from the upper layer using a pipette and was kept in the fridge at $5{ }^{\circ} \mathrm{C}$ for further usage. Dry algae powder was mixed with hexane (1:2) and homogenized using a homogenizer (Ultra turrax T25, IKA, Guangzhou, China) at 11,000 rpm for $10 \mathrm{~min}$. After this, the mix was cooled down in an ice bath and was submitted to sonication for $10 \mathrm{~min}$ using a sonicator (Fisher Scientific, Waltham, MA, USA). The mixture of AO and hexane was separated from the solids by centrifugation at $7000 \mathrm{rpm}$ for $10 \mathrm{~min}$ and the $\mathrm{AO}$ was recovered using a rotary evaporator (IKA RV10 Digital V, Guangzhou, China) at $50{ }^{\circ} \mathrm{C}$ and $150 \mathrm{~mm}$ of $\mathrm{H}_{2} \mathrm{O}$. Finally, the process was repeated three more times to recover most of the AO.

\subsection{Epoxidation of the Oils}

Epoxidized oils were prepared from pure RPO, $90 \mathrm{wt} \% \mathrm{RPO}$ and $10 \mathrm{wt} \% \mathrm{JO}$ and $90 \mathrm{wt} \% \mathrm{RPO}$ and $10 \mathrm{wt} \% \mathrm{AO}$ by in-situ epoxidation with peroxyformic acid and sulphuric acid in a molar ratio of 0.2:0.8:2.0:0.1 (double bound: organic acid: hydrogen peroxide: 
catalyst) according to Dinda et al. [6]. The calculated amount of organic acid was added to $20 \mathrm{~g}$ of oil with specific amount of catalyst and the mixture was kept at a constant temperature of $40^{\circ} \mathrm{C}$ with continuous stirring. The corresponding quantity of hydrogen peroxide was added drop wise to the mixture in order to prevent high temperature increase due to the exothermic reaction. Once the addition of hydrogen peroxide was completed, the temperature was increased to $65^{\circ} \mathrm{C}$ and the reaction was carried out for $6 \mathrm{~h}$. During this time, the formation of epoxy rings was monitored and recorded by measuring the OOC $\%$. The final epoxidized oil was cooled down at room temperature and was washed using petroleum ether and distilled water. The solvent was removed from the epoxidized oil using a rotary evaporator at $50{ }^{\circ} \mathrm{C}$ and $180 \mathrm{~mm}$ of $\mathrm{H}_{2} \mathrm{O}$.

\subsection{Hydroxylation of the Mixture}

The hydroxylation was carried out by ring opening of the epoxidized oils in the presence of methanol, water and catalyst according to Hazmi et al. [25]. Approximately $10-20 \mathrm{~g}$ of epoxidized vegetable oil was placed into a $100 \mathrm{~mL}$ three-neck flask equipped with a magnetic stirrer, a thermometer and a reflux condenser. The mixture was heated to $65^{\circ} \mathrm{C}$ with constant stirring and was left to react for $2 \mathrm{~h}$. After this, the mixture was transferred into a $250 \mathrm{~mL}$ separation funnel and was carefully washed with petroleum ether and distilled water in order to remove unreacted catalyst. Finally, the excess of water, alcohol and solvent were removed by the rotary evaporator for approximately $3-4 \mathrm{~h}$. The resulting hydroxyl value and acid value of the polyols were measured and the polyols were also analyzed using FTIR and NMR.

\subsection{Preparation of Vegetable Oil Polyurethanes}

MDI (4,4'-methylene diphenyl diisocyanate) was used to prepare polyurethane for different polyols by one shot method. The molar ratio of $\mathrm{OH}$ group to isocyanate $(\mathrm{NCO})$ was established at 1:1.6 according to the following equation:

$$
r=\frac{W_{\frac{\text { polyol }}{E W_{\text {polyol }}}}}{\frac{\left(W_{\text {Pu }}-W_{\text {polyol })}\right.}{E W_{\text {Isocyanate }}}}
$$

where, $W_{\text {polyol }}$ is the weight of the polyol, $E W_{\text {polyol }}$ is the equivalent weight of the polyol, $W_{P U}$ the weight of the produced polyurethane and $E W_{\text {Isocyanate }}$ is the equivalent weight of the isocyanate which is $125 \mathrm{~g} / \mathrm{mol}$ as supplied. The equivalent weight of the polyol was calculated as:

$$
\text { EWpolyol }=\frac{56.1 \times 1000}{\text { Acid number }\left(m g \frac{K O H}{g}\right)}
$$

The calculated amount of polyol was manually mixed at room temperature with MDI and molded into glass Petri dishes, no catalyst or other chemical was used. Afterwards, the mixture of polyol/isocyanate was left to be moisture-cured overnight in a vacuum desiccator. Finally, the polyurethane was removed and kept in a desiccator container for further analysis. This procedure was applied for all polyols (RPO, RPO $+10 \% \mathrm{JO}$ and $\mathrm{RPO}+10 \% \mathrm{AO})$.

\subsection{Analytical Procedures}

The oxirane oxygen content was measured throughout the reaction time according to AOCS official method Cd 9-57, using potassium hydrogen phthalate instead of potassium acid phthalate. Hydroxyl value (OHv) was carried out following ASTM D 427499 method C-reflux phthalation and titrated with $\mathrm{NaOH}$ solution until reaching a persisting light pink end point. The acid measurement of the vegetable polyols was determined by the MPOB method p2.5: 2004 [26] with potassium hydroxide. Finally, phospholipids from the oils ( $\mathrm{RPO}, \mathrm{AO}, \mathrm{CPO}$ ) and $\mathrm{RPO}(\mathrm{AO})$ polyol were recovered according to Goh et al. [27] using methanol and purified with acid-treated fluorisin. The quantification of phospholipids was 
conducted using a spectrophotometer at $820 \mathrm{~nm}$ according to Vaskovsky et al. [28] with modified Zinzadze's reagent.

\subsection{Spectroscopy Analysis}

The FTIR spectra was carried out using the Perkin-Elmer-spectrum with KBr plate attachment and the analysis was conducted from 4000-500 $\mathrm{cm}^{-1} \cdot{ }^{1} \mathrm{H}$ NMR was performed using an NMR spectrometer (Perkin-Elmer, LA, CA, USA) and the results were recorded at $400 \mathrm{MHz}$ using JEOL Delta.

\subsection{Gas Chromatography}

Three oil samples from $\mathrm{RPO}, \mathrm{AO}$ and $\mathrm{JO}$ were converted into the corresponding methyl esters according to the Ce 2-66 method [29], the preparation of methyl esters of fatty acids, using boron trifluoride. Then, the fatty acid composition was analyzed according to the Ce 1-62 method [30], fatty acid composition by gas chromatography, and the identification of fatty acids was undertaken using two standards from algae oil poly unsaturated fatty acid methyl ester (PUFAs) (Supelco, PA, USA) and algae oil fatty acid methyl esters (FAMEs) (Restek, PA, USA). The gas chromatography was carried out using GC-FID (Shimadzu, 2010-FID, Tokyo, Japan) and column BP-20 (SGE, Fisher Scientific, Waltham, MA, USA) with nitrogen as the carrier gas.

\subsection{Morphological Analysis}

The morphological analysis of the surface of different polyurethanes produced was conducted by scanning electron microscopy (SEM) (d4300, Hitachi, Tokyo, Japan) at 100 and $500 \mu \mathrm{m}$ magnification.

\subsection{Thermal Analysis of Polyurethanes}

The thermal degradation of the polyurethane was verified using TGA Perkin Elmer Pyris TGA thermal analyser. Approximately, $10 \mathrm{mg}$ of sample was placed into $70 \mu \mathrm{L}$ sample holder and heated from $30^{\circ} \mathrm{C}$ up to $800^{\circ} \mathrm{C}$ at a heating rate of $10^{\circ} \mathrm{C} / \mathrm{min}$ under nitrogen gas flow rate $(20 \mathrm{~mL} / \mathrm{min})$. DSC was undertaken using Perkin Elmer Pyris DSC thermal analyser according to ASTM E3418-03 as follows: heated from $25^{\circ} \mathrm{C}$ to $120^{\circ} \mathrm{C}$ at a heating rate of $10{ }^{\circ} \mathrm{C} / \mathrm{min}$, cooled to $-40{ }^{\circ} \mathrm{C}$ at $5{ }^{\circ} \mathrm{C} / \mathrm{min}$, and heated again up to $120^{\circ} \mathrm{C}$ at $10 \mathrm{C} / \mathrm{min}$ under nitrogen $\mathrm{N}_{2}$. Dynamic mechanical analysis (DMA) was carried out on DMA Q800 V20.24 with liquid nitrogen. DMA analysis was conducted according to ASTM D5062-01 standard practice. The sample of $10 \times 30 \times 1 \mathrm{~mm}^{3}$ was initially cooled to $100{ }^{\circ} \mathrm{C}$ and ramped to $140^{\circ} \mathrm{C}$ at a rate of $5^{\circ} \mathrm{C} / \mathrm{min}$ and $1 \mathrm{~Hz}$.

\section{Results and Discussion}

\subsection{Characterization of the Vegetable Oils, Epoxidized Oils and Polyols}

The free fatty acid (FFA) contents (\%) of the RPO, JO and AO are 11.21-12.57, 2.12-2.23 and 11.85-11.91 respectively while the acid values based on palmitic acid (mg $\mathrm{KOH} / \mathrm{g}$ ) are $46.44-48.89,12.4-12.75$ and 46.46-48.83 respectively. The recovered palm oil has a higher FFA content compared to crude palm oil or refined palm oil which is usually below $5 \%$ and $0.1 \%$, respectively [31]. This is obviously due to the hydrolysis and degradation of the recovered oil after exposure to the environment. On the other hand, algae oil also contain naturally high amount of FFA. The iodine value $\left(\mathrm{I}_{2} / 100 \mathrm{~g}\right)$ of the oils are 43.15-45.26, 103.62-103.69 and 116.52-118.80 for RPO, JO and AO, respectively. In comparison, the iodine values of refined palm oil is higher at around 56 due to the removal of the saturated fraction during refining [16]. The iodine values for JO were similar to results previously reported from similar oil [19]. On the other hand, The IV value for AO reported here is higher than that reported by Petrovic et al. $\left(85 \mathrm{I}_{2} / 100 \mathrm{~g}\right)$ due to the different species of algae used [32].

The fatty acids composition from the three oils used are shown in Table 1 . The highest amount of unsaturated fatty acids is from $\mathrm{AO}(81.9 \%)$ followed by JO $(78.91 \%)$ and RPO 
$(47.3 \%)$. This is in agreement with the IV values stated above. However, although algae oil content of unsaturated fatty acids is only slightly higher than that of JO, AO consists of mainly polyunsaturated fatty acids (76.9\%) from C18:2, C20:5 and C22:6 whereas JO contains only $33.29 \%$ polyunsaturated fatty acids mainly from C18:2 The highest content of mono unsaturated fatty acids was found in the JO with more than $45.62 \%$ from oleic acid (C18:1); for AO there is a low amount of mono unsaturated fatty acids with approximately $4.99 \%$ mostly from oleic and palmitoleic acid. Hence, the difference in the number of double bonds in a fatty acid backbone can affect the length of the dangling chain in the resulting polyurethane which consequently will affect the mechanical and thermal properties.

Table 1. Fatty acid profile of residual palm oil (RPO), jatropha oil (JO) and algae oil (AO) obtained from gas chromatography.

\begin{tabular}{|c|c|c|c|c|c|}
\hline \multirow{2}{*}{\multicolumn{2}{|c|}{ Compound }} & \multirow{2}{*}{ Compound Name } & \multicolumn{3}{|c|}{ Fatty Acid (\%) } \\
\hline & & & RPO & JO & AO \\
\hline \multirow{3}{*}{ Saturated } & C14:0 & Methyl myristate & 2.18 & 0.10 & 1.37 \\
\hline & C16:0 & Methyl Palmitate & 46.62 & 13.54 & 16.73 \\
\hline & C18:0 & Methyl sterate & 3.90 & 7.45 & - \\
\hline \multirow{2}{*}{ Mono unsaturated } & C14:1 & Methyl myristoleate & - & - & 0.88 \\
\hline & C16:1 & Methyl Palmitoleate & - & 0.69 & 1.95 \\
\hline \multirow{5}{*}{ Polyunsaturated } & C18:1n9 & Methyl oleate & 37.93 & 44.93 & - \\
\hline & C22:1n9 & Methyl erucate & - & - & 2.16 \\
\hline & C18:2n6 & Methyl linoleate & 9.37 & 33.29 & 21.05 \\
\hline & $\mathrm{C} 20: 5 \mathrm{n} 3$ & Methyl eicosapentaenoate & - & - & 52.57 \\
\hline & C22:6n3 & Methyl docosahexaenoate & - & - & 3.28 \\
\hline
\end{tabular}

The fatty acid profile of algae oil also differs greatly for different species and different growing conditions [33]. The oil from Chlorella vulgaris contains a much longer hydrocarbon chain (C20:5) with five double bonds in its backbone. In comparison, algae oil from another Chlorella species reported by Pawar et al. [20] contains predominantly C18 hydrocarbon $(64 \%)$ with one double bond (C18:1). Hence, there is a great variation in the chemical structure of the algae triglyceride which is known to impact the properties of the resulting polyurethane.

\subsection{Analysis of Phospholipids}

Table 2 shows the results obtained from the detection of phospholipids in $\mathrm{RPO}, \mathrm{AO}$, JO and $\mathrm{RPO}(\mathrm{AO})$ polyol. AO contains a very high concentration of phospholipids compared to JO and RPO. According to Gurr and Brawn [34], phosphate in AO from Chlorella vulgaris is mostly presence in the form of phosphatidyl choline from the diglycerides of C16:0, C18:1, C18:2 and C:18:3 fatty acids, which are the main reactive groups during polymerization. The addition of algae oil containing a high amount of phosphate as additive can significantly increase the thermal stability and fire-retardant properties of the final biopolymer as explained by Lewis A. [35]. However, it is apparent that the concentration of phospholipids in the polyol from $\mathrm{RPO}(\mathrm{AO})$ is significantly reduced from the original content in the $\mathrm{AO}$. This reduction could be due to the formation of water-phospholipid emulsion during washing after epoxidation and hydroxylation process. The low content of phospholipids in JO and RPO indicates that only a small concentration of phospholipids will end up in the polyols and the final PU from JO and RPO.

The phospholipid content found in this study was, however, lower than that found in literatures. Nichols B. [36] showed that algae oil from Chlorella vulgaris contains around $30 \% w / w$ of phospholipid from diglycerides of phosphatidyl choline and phosphatidyl ethanolamine among others under normal light growing conditions. Similarly, Rao et al. [37] found that jatropha oil seeds contain approximately $1.4 \mathrm{wt} \%$ of phospholipids which is significantly higher than the value found in this study. This is possibly due to the extraction method used in this study in which hexane was used as the solvent to recover 
the maximum amount of oil. As hexane is a highly non-polar solvent, it is expected that less phospholipid will be extracted compared to using other more polar solvents used in the studies mentioned above [36,37].

Table 2. Phospholipid content in different oil samples and RPO(AO) polyol.

\begin{tabular}{cccc}
\hline Sample & Sample (g) & $\boldsymbol{\lambda} \mathbf{8 2 0} \mathbf{n m}$ & ppm \\
\hline AO & 1.009 & $1.709 \pm 0.16$ & $6237 \pm 582$ \\
JO & 0.909 & $0.518 \pm 0.13$ & $92.51 \pm 17$ \\
RPO & 1.015 & $0.812 \pm 0.01$ & $98.18 \pm 0.19$ \\
RPO(AO) polyol & 1.005 & $1.832 \pm 0.35$ & $235.7 \pm 42.37$ \\
\hline
\end{tabular}

\section{3. $H^{1}$ Nuclear Magnetic Resonance (NMR) Spectra of the Vegetable Oils}

The proton $\left(\mathrm{H}^{1}\right)$ spectrum of the $\mathrm{RPO}, \mathrm{AO}$ and JO are shown in Figure 1 and the peaks assignation is shown in Table 3. The analysis of the signals was conducted according to Gustone F. [38], Hatzakis et al. [39] and Aung et al. [19]. Several similarities are shown in the structure of the different oils which are basically constituted of glyceride bone and acyl chains (i.e., fatty acid chains) with different unsaturation degrees. For example, in the spectrum of JO the strongest peak corresponds to alkenyl group (signal No. 1). However, in $\mathrm{AO}$ the peak found for double allycil groups (signal No. 2) is higher than signal No1. For AO, strong peaks were found in high amount between $\delta=3.3$ to 4 which are distinctive peaks from the hydrogen-choline compounds found in vegetable oil phospholipids. Unfortunately, the separation in this range was not completed because of the low solubility of phospholipid compounds with the solvent used during the analysis (i.e., chloroform). According to Hatzakis et al. [39], the peak found at 3.8 corresponds to protons on the fatty acyl chain of phosphtidylcholine (PC) and the peak found at 8.4 is related to the ${ }^{+} \mathrm{NH}_{3}$ group from phosphtidylethanolamine (PDA). Hence, the $\mathrm{H}^{1} \mathrm{NMR}$ for the different oils is in agreement with the analytical procedure described above in which the highest concentration of phospholipids was found in $\mathrm{AO}$ and zero to low amounts in $\mathrm{RPO}$ and JO.

Table 3. Signal number, hydrogen assignation and group of oils by $\mathrm{H}^{1} \mathrm{NMR}$.

\begin{tabular}{|c|c|c|c|}
\hline Signal & Proton & $\delta$ & Assignation of Hydrogen Atoms \\
\hline 1 & $(-\mathrm{CH}=\mathrm{CH}-)$ & 5.33 & All alkenyl \\
\hline 2 & $(=\mathrm{CHCH} 2 \mathrm{CH}=)$ & 2.81 & doubly allylic \\
\hline 3 & $-\mathrm{CH}_{2} \mathrm{CH}_{2} \mathrm{COOCH}_{3}$ & 2.28 & Acyl chains \\
\hline 4 & $\mathrm{CH}_{2} \mathrm{CH}=\mathrm{CHCH}_{2-}^{-}$ & 2.03 & Allylic chains \\
\hline 5 & $\left(\mathrm{CH}_{2}\right)_{\mathrm{n}}$ & 1.28 & Acyl chains \\
\hline 6 & $\mathrm{CH}_{2} \mathrm{CH}_{2} \mathrm{CH}_{2}-\mathrm{CH}_{3}$ & $1.58 / 0.8$ & Acyl chains excluding linolenyl \\
\hline 7 & $\mathrm{CH}_{2}-\mathrm{OCOR}$ & $4.12 / 4.31 / 4.41 / 5.20$ & Glycerol \\
\hline A & $\mathrm{CH}_{2}-\mathrm{OP}(\mathrm{O})_{2} \mathrm{O}$ & 3.94 & Glycerol/Choline \\
\hline $\mathrm{B}$ & $\mathrm{CH}_{2}-\mathrm{N}\left(\mathrm{CH}_{3}\right)_{3}$ & 3.81 & Choline \\
\hline $\mathrm{C}$ & $-\mathrm{N}\left(\mathrm{CH}_{3}\right)_{3}$ & 3.36 & Choline \\
\hline $\mathrm{D}$ & $\mathrm{CH}_{2}-{ }^{+} \mathrm{NH}_{3}$ & 8.4 & Anolamine \\
\hline
\end{tabular}

\subsection{Oxirane Oxygen Content (OOC\%)}

The analysis of $\mathrm{OOC} \%$ of $\mathrm{RPO}, \mathrm{RPO}(\mathrm{JO})$ and $\mathrm{RPO}(\mathrm{AO})$ during the epoxidation process is presented in Figure 2. The graph shows the increment of epoxy groups after the inclusion of oxygen into the unsaturated bond of the different oils. The process continued until the maximum OOC was achieved and it was followed by ring opening of the cyclic ethylene oxide which led to reduction in OOC. The epoxidize RPO (ERPO) without additive showed the lowest speed of reaction, the shortest time to reach maximum OOC, and the lowest maximum OOC. This might be due to the low degree of unsaturation of the RPO. However, 
the addition of $10 \% \mathrm{AO}$ and JO to the RPO significantly increase the OOC value as well as the reaction time.
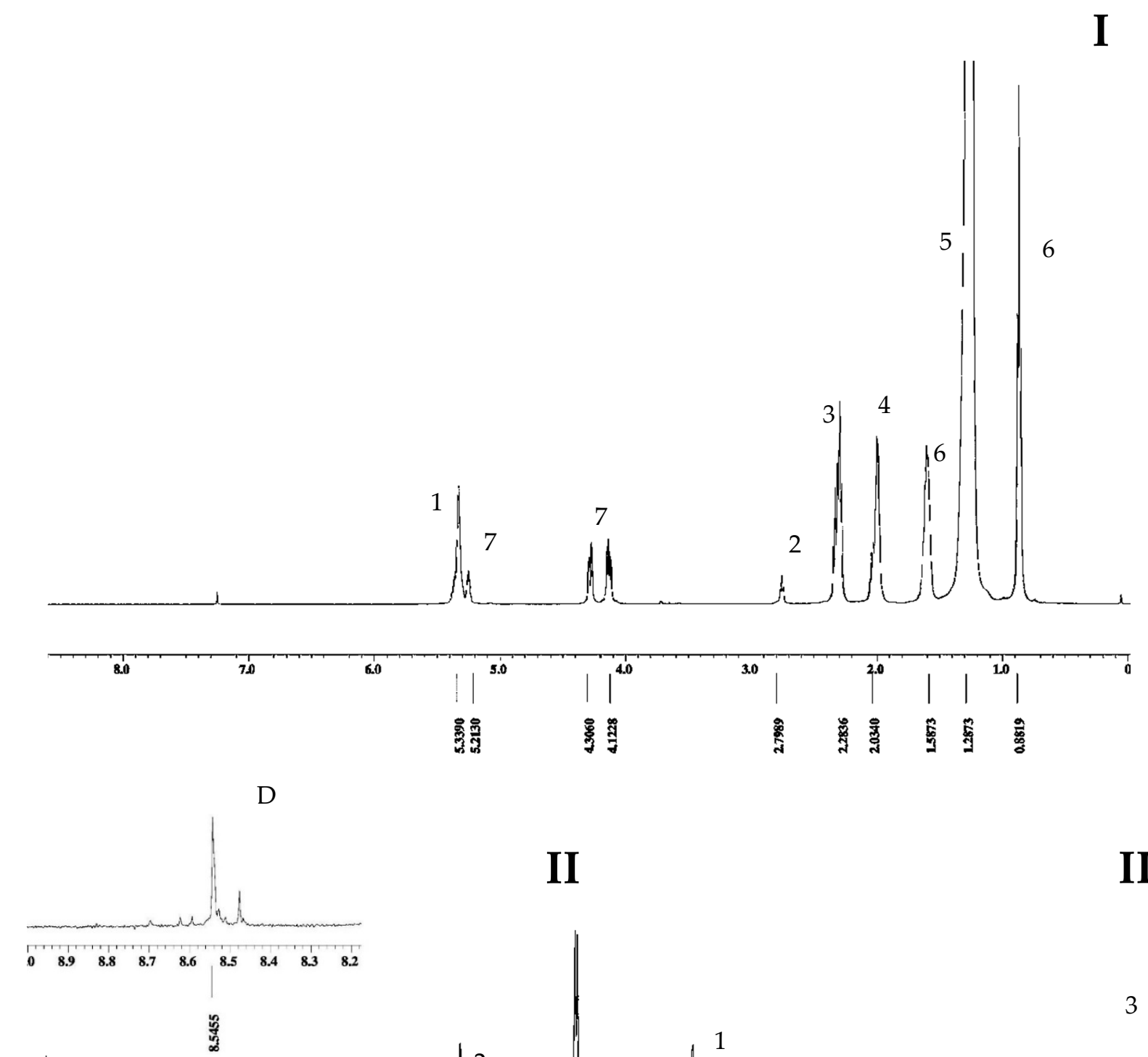

III
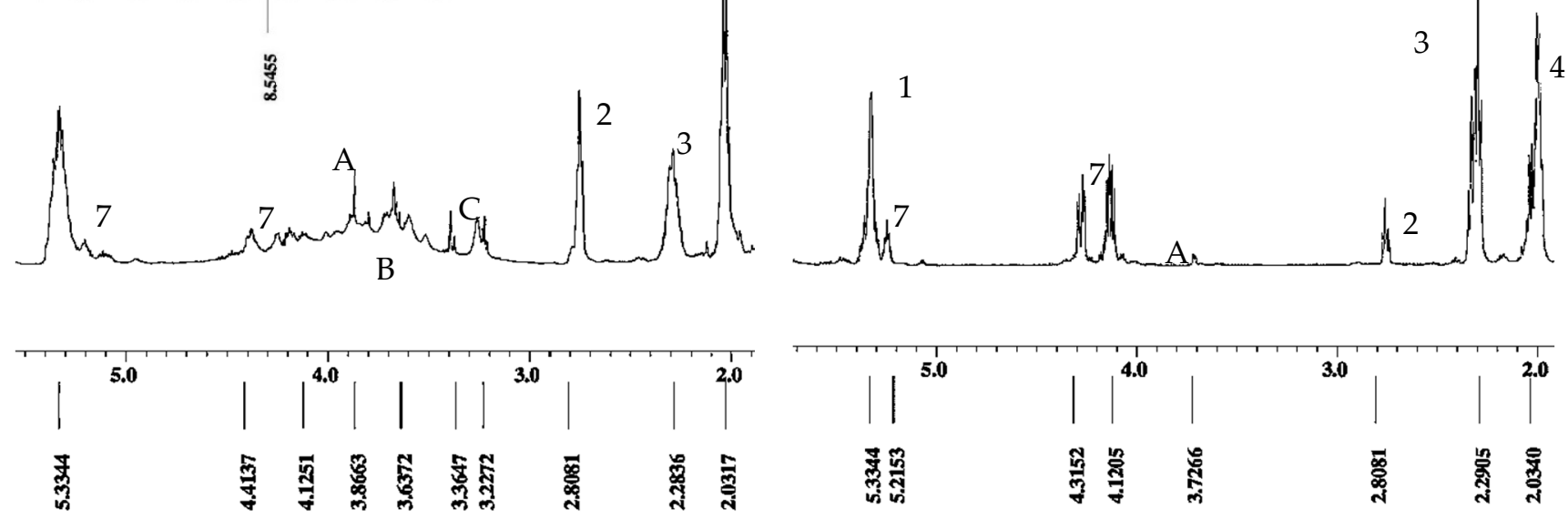

Figure 1. $\mathrm{H}^{1}$ nuclear magnetic resonance (NMR) spectrum of RPO (I), AO (II) and JO (III). 


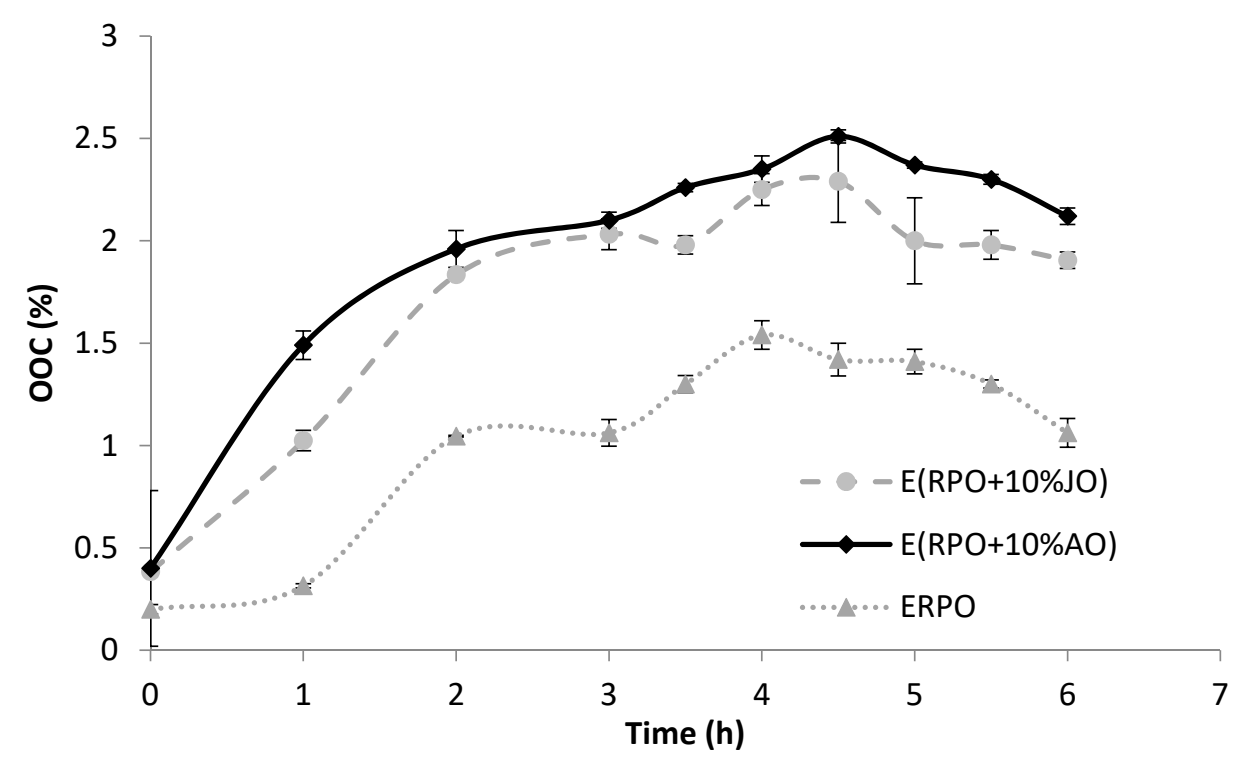

Figure 2. Analysis of OOC (oxirane oxygen content) during epoxidation of RPO, RPO $+10 \% \mathrm{JO}$ and $\mathrm{RPO}+10 \% \mathrm{AO}$.

Table 4 shows the characterization of residual palm-based epoxy and polyols with and without additive. Based on the result, the addition of only $10 \% \mathrm{AO}$ and $\mathrm{JO}$ as additive increases approximately $40 \%$ and $30 \%$ the OOC of epoxidized RPO(AO) [ERPO(AO)] and epoxidized RPO(JO) [ERPO(JO)] compared to epoxidized pure RPO (ERPO), respectively. However, the maximum OOC values obtained in this study are lower compared to the theoretical OOC calculated using the IV value of each oil according to Hazmi et al. [25]. All the samples have similar oxirane conversion with a yield of 60 to $70 \%$ OOC. Finally, the value of IV in the epoxidized samples indicated that the epoxidation process was incomplete and that a certain number of ethilenic groups did not react and optimization of the reaction is required.

Table 4. Properties of the epoxidized residual palm oil (RPO), RPO with $10 \%$ algae oil (AO) and RPO with $10 \%$ jatropha oil (JO). ${ }^{1}$ Value calculated according to Hazmi et al. [25].

\begin{tabular}{cccc}
\hline Property & \multicolumn{3}{c}{ Epoxidized } \\
\cline { 2 - 4 } & RPO & RPO(JO) & RPO(AO) \\
\hline OOC_max, (\%) & - & - & - \\
Acid Value (mg KOH/g) & $1.65 \pm 0.11$ & $2.33 \pm 0.04$ & $2.745 \pm 0.23$ \\
IV, \% per mole & $29.395 \pm 0.47$ & $6.46 \pm 0.7$ & $12.2 \pm 1.14$ \\
OOC Max. Theoretical & $17.6 \pm 0.25$ & $11.05 \pm 0.28$ & $3.43 \pm 0.11$ \\
& $2.71 \pm 0.06$ & $3.53 \pm 0.02$ & $3.975 \pm 0.35$ \\
\hline Hydroxyl value (mg KOH per gram) & & hydroxylated & $152.06 \pm 0.56$ \\
Equivalent weight & $78.525 \pm 1.29$ & $131.34 \pm 2.68$ & $62.40 \pm 0.02$ \\
\hline
\end{tabular}

In addition, the acid value from the $\mathrm{ERPO}(\mathrm{AO})$ was shown to be higher than the ERPO(JO). Naturally, AO contains high acid value which can interfere with the polymerization due to the reaction with $(\mathrm{N})$ isocyanate instead of the $\mathrm{OH}$ form polyol. Nevertheless, this might be minimized due to the high $\mathrm{OH}$ obtained from the polyunsaturated $\mathrm{AO}$. Finally, the value of $\mathrm{OH}$ obtained from $\mathrm{RPO}$ was higher than values reported from untreated crude palm oil CPO $(50 \mathrm{mg} \mathrm{KOH} / \mathrm{g})$, but, it is lower than the value reported for refined, bleached and deodorized (RBD) palm olein which was found to be $110 \mathrm{mg} \mathrm{KOH} / \mathrm{g}$ [40]. The $\mathrm{OH}$ value of $\mathrm{RPO}(\mathrm{AO})$ polyol is almost double that of $\mathrm{RPO}$ polyol again showing that the addition of $10 \%$ algae oil increases the hydroxyl value of the polyol significantly. 


\subsection{Fourier Transform Infrared (FTIR) Analysis of Different Polyols}

FTIR of the epoxidized oils after hydroxylation is presented in Figure 3 and the FTIR analysis was reported according to Aung et al. [19]. The formation of polyol for all the oil samples was corroborated with the characteristic hydroxyl band observed at $3475 \mathrm{~cm}^{-1}$. It was found that the hydroxyl peak obtained from $\mathrm{RPO}(\mathrm{AO})$ was the highest which confirms the result of hydroxyl values in Table 3. The vibrations attributed to $\mathrm{CH}_{2}$ bending, $-\mathrm{CH}$ bends, and $\mathrm{CH}_{2}$, were found at 1464,1407 and $1311 \mathrm{~cm}^{-1}$ absorption bands, respectively and could be attributed to the fatty acid chains of the triglycerides. It was found that the $\mathrm{RPO}(\mathrm{AO})$ polyol showed the highest area at these bands followed by RPO(JO) and RPO. This can be due to the longer fatty acid chains' present in AO (i.e., fatty acids from C22 and C25). In addition, characteristic bands of the hydroxyl and carbonyl groups were found in the 3373 and $1750 \mathrm{~cm}^{-1}$ region. Finally, no apparent peak from ethylenic bonds was found at $1630-1640 \mathrm{~cm}^{-1}$ which might indicate that remaining double bonds could be opened during polyol reaction due to high temperature used. (e.g., $90^{\circ} \mathrm{C}$ ) (Lai et al., 2013).

$$
\text { - - - - RPO (RPO+10\%AO)Polyol ……….... (RPO+10\%JO)Polyol }
$$

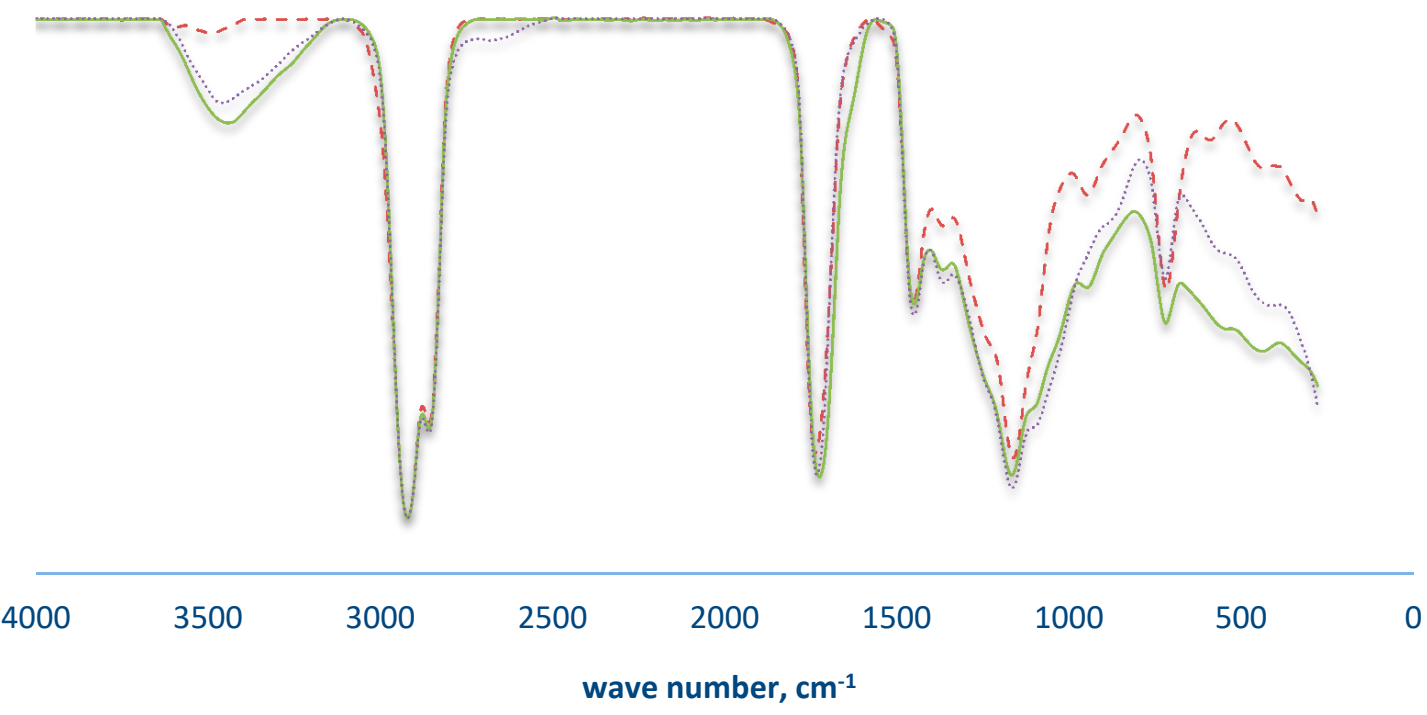

Figure 3. Hydroxylation of RPO, RPO $+10 \% \mathrm{JO}$ and $\mathrm{RPO}+10 \% \mathrm{AO}$ polyols is described by Fourier transform infrared (FTIR) spectra.

\section{6. $H^{1} N M R$ Analysis of $R P O(A O)$ Polyol Formation}

The hydroxylation of $\mathrm{RPO}(\mathrm{AO})$ oils was corroborated by $\mathrm{H}^{1} \mathrm{NMR}$. Figure 4 , shows the pathway of $\mathrm{RPO}(\mathrm{AO})$ to epoxidized oil and to hydroxylated polyol, analyzed by NMR spectra. The identification of phosphate, unsaturated, epoxy and hydroxyl groups are highlighted with less attention to other groups shown previously. As mentioned before, the structure of the different oils before processing is similar however, $\mathrm{AO}$ can provide phosphate groups to the final polyol and to the subsequent polyurethane. During the epoxidation and hydroxylation of the oils it is possible to identify the formation of epoxy rings at $4.3 \mathrm{ppm}$ (Figure $4 \mathrm{~B}$ ) and hydroxyl carbon at $3.65 \mathrm{ppm}$ (Figure $4 \mathrm{C}$ ) which is in accordance with previous reported analysis [19]. However, in all the NMR shown it is possible to identify one small peak at $\delta=5.33$ of alkenyl unsaturation which indicates that the epoxidation was not complete as shown in the analysis of IV (This peak was not clear in the FTIR analysis of the RPO(AO) polyol). Finally, the protons of phosphate groups were found in the final polyol from $\mathrm{RPO}(\mathrm{AO})$ which agrees with the analysis above. 


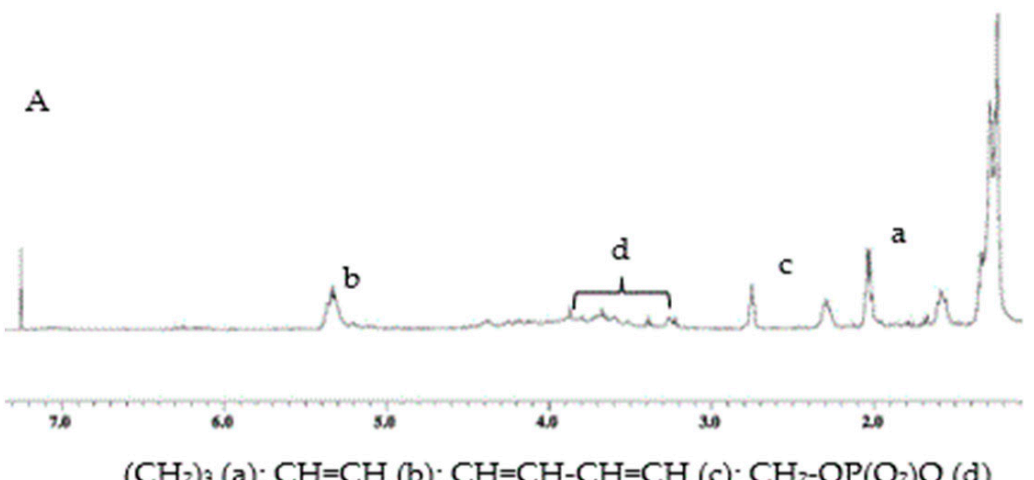

B

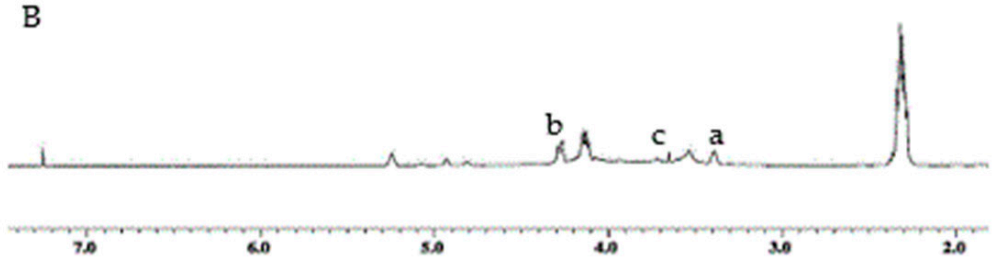

$\mathrm{O}-\mathrm{CH}-\mathrm{CH}_{2}-\mathrm{CH}-\mathrm{O}(\mathrm{a}) ; \mathrm{CH}-\mathrm{O}-\mathrm{CH}(\mathrm{b}) ; \mathrm{CH}_{2}-\mathrm{OP}\left(\mathrm{O}_{2}\right) \mathrm{O}$ (c)

C

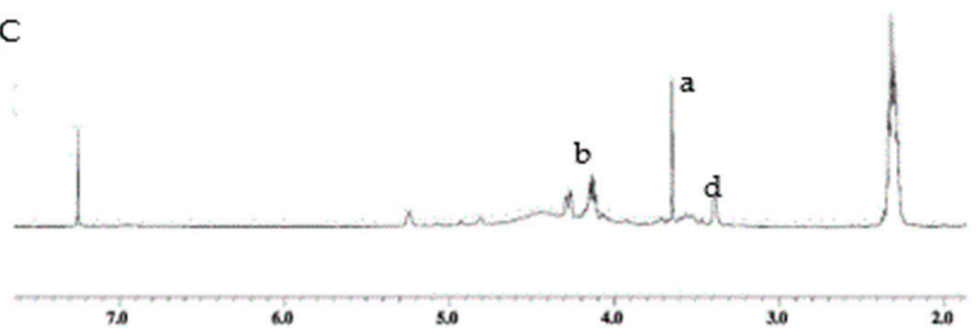

$\mathrm{C}-\mathrm{OH}(\mathrm{a}) ; \mathrm{CH}-\mathrm{OH}(\mathrm{b}) ;\left(\mathrm{CH}_{2}\right) 3(\mathrm{c}) ; \mathrm{CH}_{2}-\mathrm{OP}\left(\mathrm{O}_{2}\right) \mathrm{O}$ (d)

Figure 4. Pathway of the hydroxylation of $\mathrm{RPO}(\mathrm{AO})$ analyzed by $\mathrm{H}^{1} \mathrm{NMR}$ showing the oil $\mathrm{RPO}(\mathrm{AO})$ (A), the epoxidized $\mathrm{RPO}(\mathrm{AO})(\mathbf{B})$ and $\mathrm{RPO}(\mathrm{AO})$ polyol $(\mathbf{C})$.

A polyurethane linkage is created by reacting the poly isocyanate group, $-\mathrm{N}=\mathrm{C}=\mathrm{O}$, with the hydroxyl $(-\mathrm{OH})$ group in the polyalcohol (polyol) in the presence of a catalyst (Scheme 1) [41]. Hence, when more hydroxyl groups are presented in the polyol more linkages will be obtained in the polymer. Furthermore, the hydroxyl number of the polyols has a linear effects on crosslinking density of the poly-urethanes, expressed as the number of elastically active network chains per unit volume, and inversely proportional to the average molecular weight between crosslinks which resulted in better mechanical properties [4].

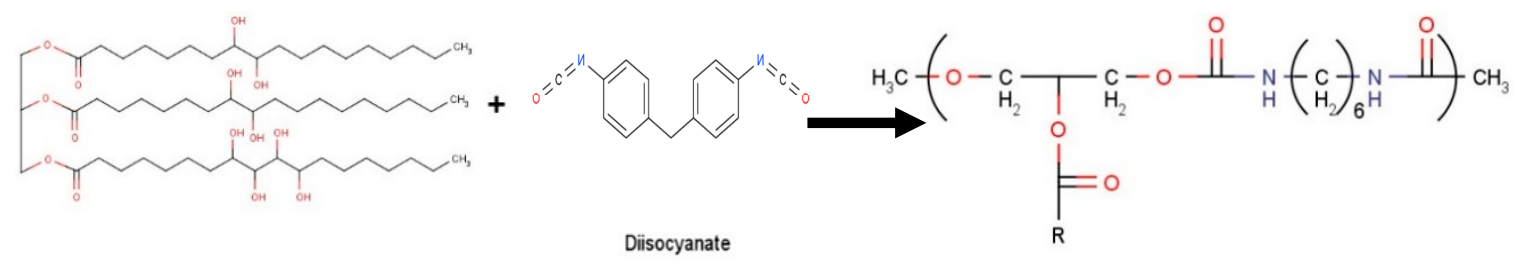

Polyol

Polvurethane

Scheme 1. Urethane linkage.

3.6.1. Spectroscopy Analysis of Polyurethanes (FTIR)

The produced polyurethanes (PU) were analyzed by FTIR spectroscopy to identify their structure and the respective polymerization. Three different PU from RPO, 
$\mathrm{RPO}+10 \% \mathrm{AO}$ and $\mathrm{RPO}+10 \% \mathrm{JO}$ were prepared, analyzed by FTIR according to Velencoso et al. [42] and the results are shown in Figure 5. The stretching vibrations at $3325 \mathrm{~cm}^{-1}$ were identified as characteristic bands of $\mathrm{N}-\mathrm{H}$ from the urethanes linkages. The PU from RPO with $\mathrm{AO}$ as additive showed the highest intensity compared to other PU. This indicates that a higher urethane linkage was obtained with $\mathrm{AO}$ at the same $\mathrm{NCO}: \mathrm{OH}$ ratio. The unreacted NCO compounds were identified at $2290 \mathrm{~cm}^{-1}$ and shown to be similar in the three samples. Stretches at 2920 and 2853 were found for the $\mathrm{C}-\mathrm{H}$ methane group as asymmetric and symmetric. The large difference between the peaks in the 3325 and 2920 region indicates that the three consist mostly of semi rigid and soft PU rather than hard sections. In addition, according to Zhang et al. [43] the stretching vibration at $1029 \mathrm{~cm}^{-1}$ indicates the presence of $\mathrm{P}-\mathrm{O}-\mathrm{C}$ symmetric bending vibration. This peak is clearly present in PU from $\mathrm{RPO}(\mathrm{AO})$ which can be attributed to the presence of phospholipid in the AO. No peak in the bands for the $\mathrm{OH}$ group $\left(3400 \mathrm{~cm}^{-1}\right)$ was found which indicates that all the available $\mathrm{OH}$ groups reacted with the MDI to form the PU. Also, no stretch corresponding to urea bands $\left(1628-1690 \mathrm{~cm}^{-1}\right)$ was found.

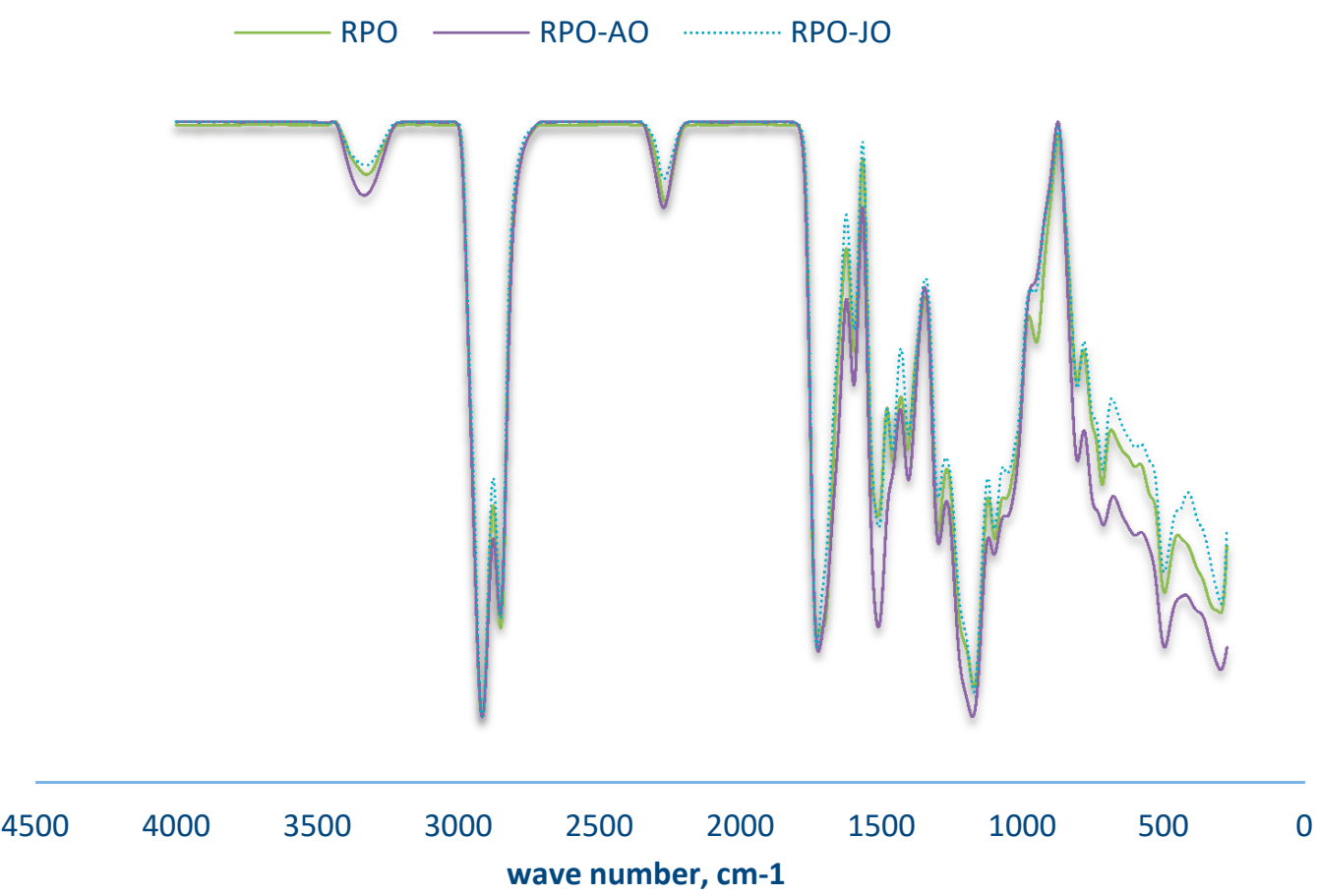

Figure 5. FTIR spectra of the polyurethanes produced by RPO, RPO $+10 \% \mathrm{JO}$ and RPO $+10 \% \mathrm{AO}$ polyol with isocyanate.

\subsubsection{Morphological Analysis}

The surface of the polyurethane obtained from hydroxylated RPO, RPO $+10 \% \mathrm{JO}$ and $\mathrm{RPO}+10 \% \mathrm{AO}$ was scanned by using SEM (d4300, Hitachi, Japan) and the results are shown in Figure 6. The surface of the polyurethane obtained from RPO (Figure 6a) showed an amorphous growing of several spike shapes without specific orientation (Figure 6d). The formation of amorphous spike shapes caused cracks which weaken the polymer [44]. On the other hand, the addition of polyunsaturated oil such as JO (Figure $6 \mathrm{~b}$ ) to the original RPO significantly reduced the formation of spike shapes with better orientation. A smoother surface was obtained when the RPO was blended with $10 \% \mathrm{AO}$ (Figure $6 \mathrm{c}$ ). 
a.

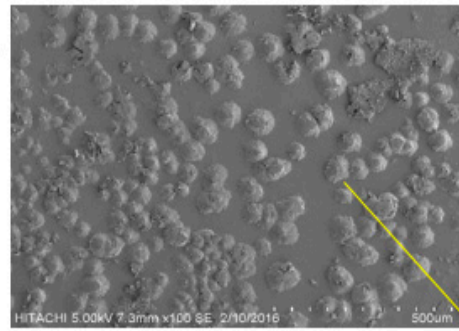

b

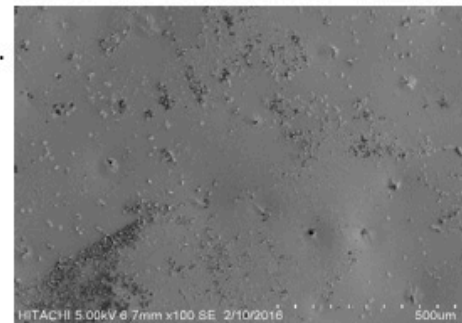

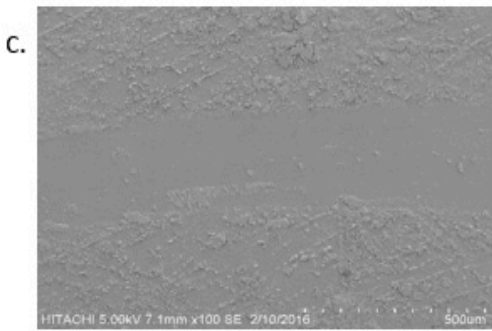

d.

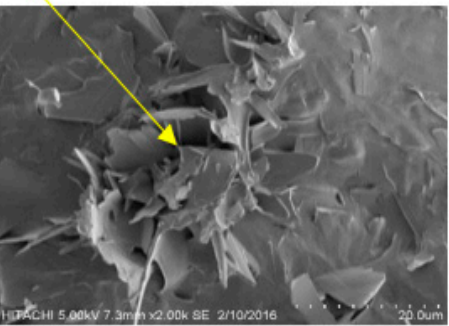

Figure 6. Surface of the polyurethanes using scanning electron microscopy (SEM, 5.0 KV:500 $\mu$ m magnification) obtained from the polyols of (a) RPO (b) RPO + 10JO (c) RPO + 10\%AO and (d) RPO with SEM (5.0 KV:100 $\mu$ m magnification).

\subsection{Polymer Thermal Analysis}

3.7.1. Differential Scanning Calorimeter (DSC)

Figure 7 shows the analysis of DSC of the different polyurethanes synthesized while Table 5 summarizes the values obtained for $\mathrm{T}_{\mathrm{g} 1}$ and $\mathrm{T}_{\mathrm{g} 2}$ for the soft segment and hard segment of the different PU produced. The change of slope on the DSC shows that there is one glass transition temperature $T_{\mathrm{g} 1}$ for soft segments and one $T_{\mathrm{g} 2}$ for hard segments without melting peak, indicating that the samples have an amorphous structure [45]. The lowest $\mathrm{T}_{\mathrm{g} 1}$ was obtained from $\mathrm{RPO}(\mathrm{AO})$ at $-33.3^{\circ} \mathrm{C}$, followed by $\mathrm{RPO}(\mathrm{JO})$ at $-25.8^{\circ} \mathrm{C}$ and $\mathrm{RPO}$ at around $-25.6^{\circ} \mathrm{C}$. All samples exhibit similar $\mathrm{T}_{\mathrm{g} 1}$ because of the similar main source used (i.e., palm oil) and are similar to other palm-based bio polymers developed by other researchers (e.g., -33 to $-15^{\circ} \mathrm{C}$ ) [46]. However, $\mathrm{RPO}(\mathrm{AO})$ exhibit slightly lower Tg1 possibly due to the longer fatty acid chains that have higher mobility at lower temperature.

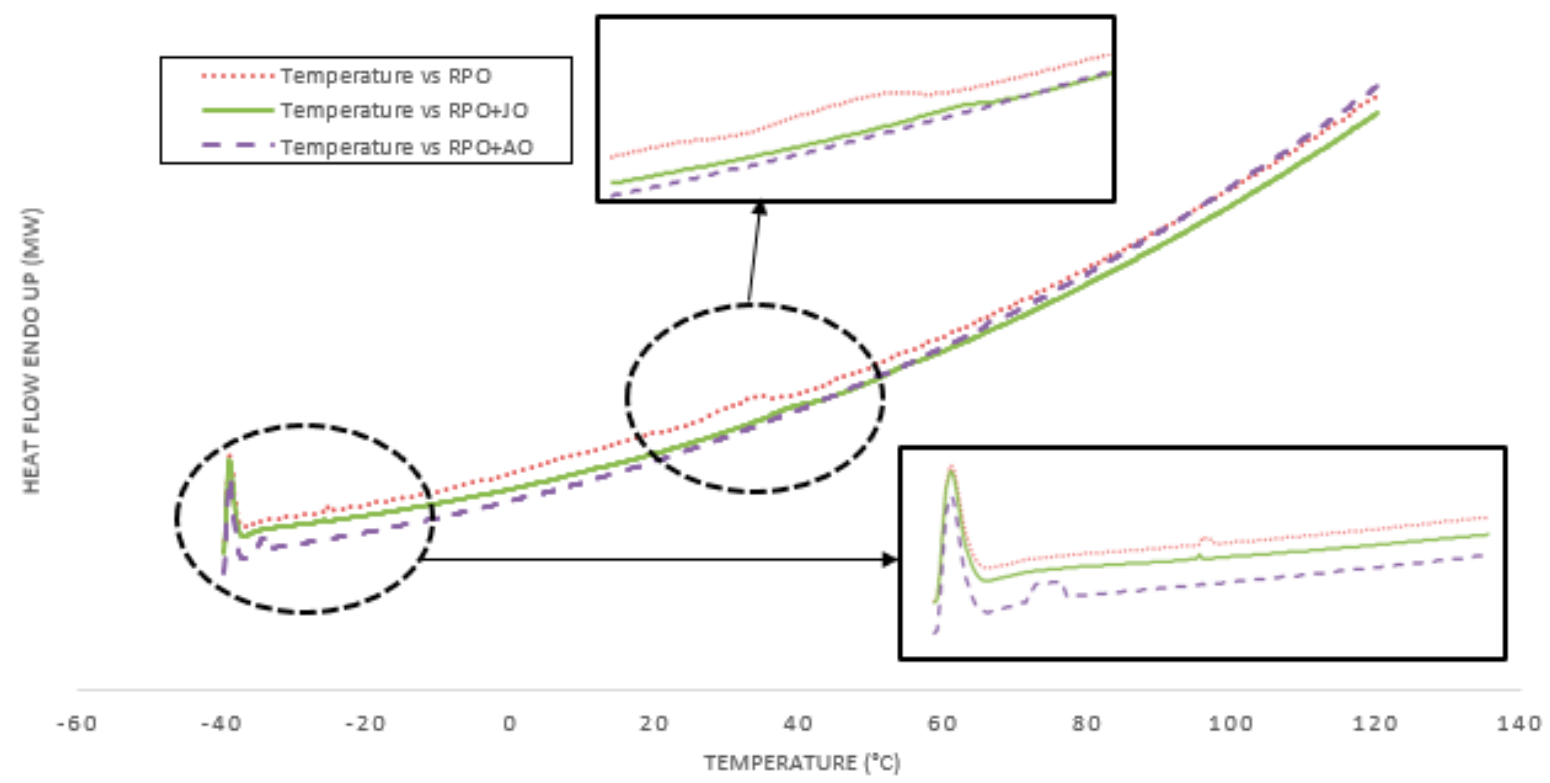

Figure 7. Differential scanning calorimetry (DSC) curve of polyurethanes from vegetable oils. 
The negative values of $\mathrm{T}_{\mathrm{g} 1}$ suggest that all the PUs are dominant in flexible segments provided by the long fatty acid chains of the vegetable oils. When AO is added to the RPO as additive, this might add flexibility, increase elongation at break and resistance to scratching to the final PU. In addition, the lower value of $\mathrm{T}_{\mathrm{g} 1}$ from $\mathrm{RPO}(\mathrm{AO})$ can also be related to the inclusion of phosphate groups in final PU. Wu et al. [47] compared the $\mathrm{T}_{\mathrm{g}}$ obtained from different PU before and after the addition of tris(chloroisopropyl) phosphate (TCPP) as a flame retardant plasticizer. They obtained significant reduction of $\mathrm{T}_{\mathrm{g}}$ per percentage of TCPP added as plasticizer due to the swelling of the PU structure, effect of the phosphate group and dilution of aromaticity (i.e., reaction with $\mathrm{NCO}$ ).

Table 5. Glass transition temperature $\left(\mathrm{T}_{\mathrm{g} 1}\right.$ and $\left.\mathrm{T}_{\mathrm{g} 2}\right)$ obtained under and over $0{ }^{\circ} \mathrm{C}$, respectively, from residual palm oil (RPO); RPO with 10\% algae oil RPO(AO); RPO with $10 \%$ jatropha oil RPO(JO); compared with jatropha oil (JO) reported by Saalah, S. (2016) [48] ${ }^{\mathrm{a}}$.

\begin{tabular}{ccc}
\hline Sample & $\mathbf{T}_{\mathbf{g} 1}$ & $\mathbf{T}_{\mathbf{g} 2}$ \\
\hline $\mathrm{RPO}$ & -25.6 & 27.8 \\
$\mathrm{RPO}(\mathrm{JO})$ & -25.8 & 35.3 \\
$\mathrm{RPO}(\mathrm{AO})$ & -33.3 & 37.5 \\
$\mathrm{JO}^{\mathrm{a}}$ & -11.45 & - \\
\hline
\end{tabular}

The effect of hard segments in the sample and the relation with $\mathrm{T}_{\mathrm{g} 2}$ can be correlated with the increasing of the $\mathrm{OH}$ number in the polyol. All the samples exhibited hard segments due to the crosslinking with urethane groups. However, the high $\mathrm{OH}$ value found in the $\mathrm{AO}$ leads to the production of more hard segments between the polyol and the isocyanate which restricted the chain mobility and increased $\mathrm{T}_{\mathrm{g} 2}$.

\subsubsection{Thermo Gravimetrical Analysis (TGA)}

The degradation of the PUs with temperature was analyzed using TGA and the results are shown in Figure 8. The first degradation (TD1) is associated with the loss of moisture content and suggests that the degradation of $\mathrm{PU}$ from $\mathrm{RPO}(\mathrm{AO})$ is slightly faster compared to other PUs due to possible water emulsion trapped in the phospholipid groups. The second onset of degradation of the PU (TD2) from all samples started at 250 to $300{ }^{\circ} \mathrm{C}$ which is associated with the hard segments on the PU [20]. It can be seen that the PU from RPO degrades much faster possibly due to higher saturation and less urethane linkage that is formed [13] and possible free isocyanate [49]. PU from RPO/JO and RPO/AO degrades at a similar rate during this stage. The third degradation stage (TD3) started at $350{ }^{\circ} \mathrm{C}$ for RPO and at $420{ }^{\circ} \mathrm{C}$ for RPO(AO) and RPO(JO). At this stage, the decomposition of the polyol soft segment occurred. The degradation rate and the percentage of weight loss of $\mathrm{RPO}(\mathrm{AO})$ is the slowest which could be due to longer fatty acid chains of AO that are squeezed out of the PU matrix during curing and the phosphate plasticizer in the AO. Hence, the usage of $\mathrm{AO}$ as additive was shown to significantly improve the stability of the polymer at high temperature.

Table 6 shows the degradation at 5\%,10\% weight loss ratio and max residual amount of material remaining after the thermal decomposition versus the temperature measured. The initial stage of degradation (i.e., 5\% weight loss) occurred at a higher temperature for the sample with RPO compared with the other polymers possibly due to less phospholipid concentration. As mentioned before, the phospholipids might have created water-oil emulsions during the epoxidation process trapped inside the polymer and not removed during the drying process of the samples. The next 10 percentage weight loss show the highest temperature for the sample with JO followed by the sample with AO, which correlates with a higher degree of polymerization when compared to RPO. Finally, the three samples flatten the curve of weight loss (Final weight) at different temperatures and with different sample char residual. The sample with AO presented the highest char residual with $20.96 \%$ possibly due to the highest concentration of phosphatide presented in the $\mathrm{AO}$. 


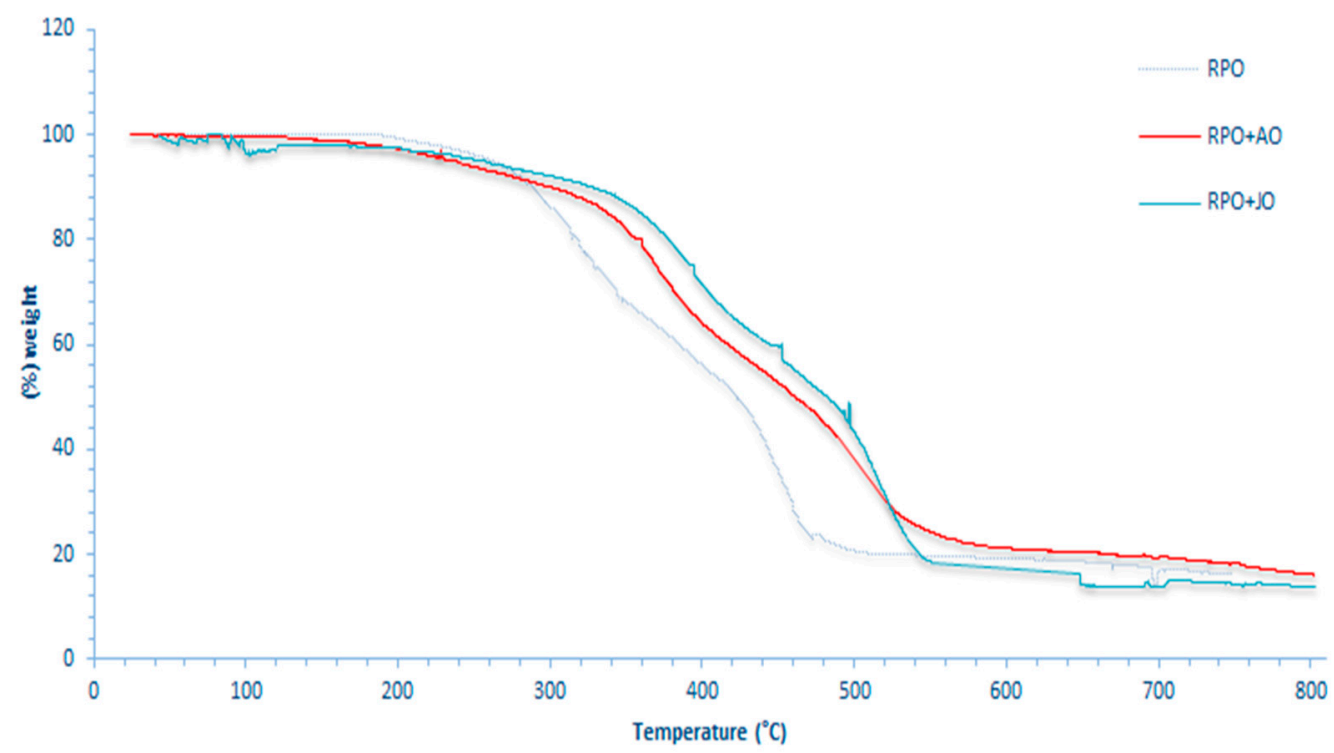

Figure 8. Overlay of thermogravimetric analysis (TGA) curves of the palm-based bio-polyurethanes produced.

Table 6. The 5, 10 and max percentage of weight loss versus temperatures for the samples with RPO, $\mathrm{RPO}(\mathrm{JO})$ and $\mathrm{RPO}(\mathrm{AO})$.

\begin{tabular}{cccc}
\hline \multirow{2}{*}{ Weight Loss (\%) } & \multicolumn{3}{c}{ Temperature $\left({ }^{\circ} \mathbf{C}\right)$} \\
\cline { 2 - 4 } & RPO & RPO(JO) & RPO(AO) \\
\hline 5 & 261.33 & 239.54 & 234.10 \\
10 & 288.02 & 312.05 & 305.56 \\
max & 516.23 & 550.34 & 669.53 \\
\hline Sample residual (\%) & 16.11 & 18.53 & 20.96 \\
\hline
\end{tabular}

\subsubsection{Dynamic Mechanical Analyzer (DMA)}

DMA was conducted to analyze the mechanical and viscoelastic behavior of the three different materials under thermodynamic changes. Figure 9, depicts the dependence of the loss factor and the storage modulus (i.e., tan delta) with temperature. The continuous increment of tan delta might be due to accretion of the molecular chain mobility that soften the polymer at an elevated temperature.

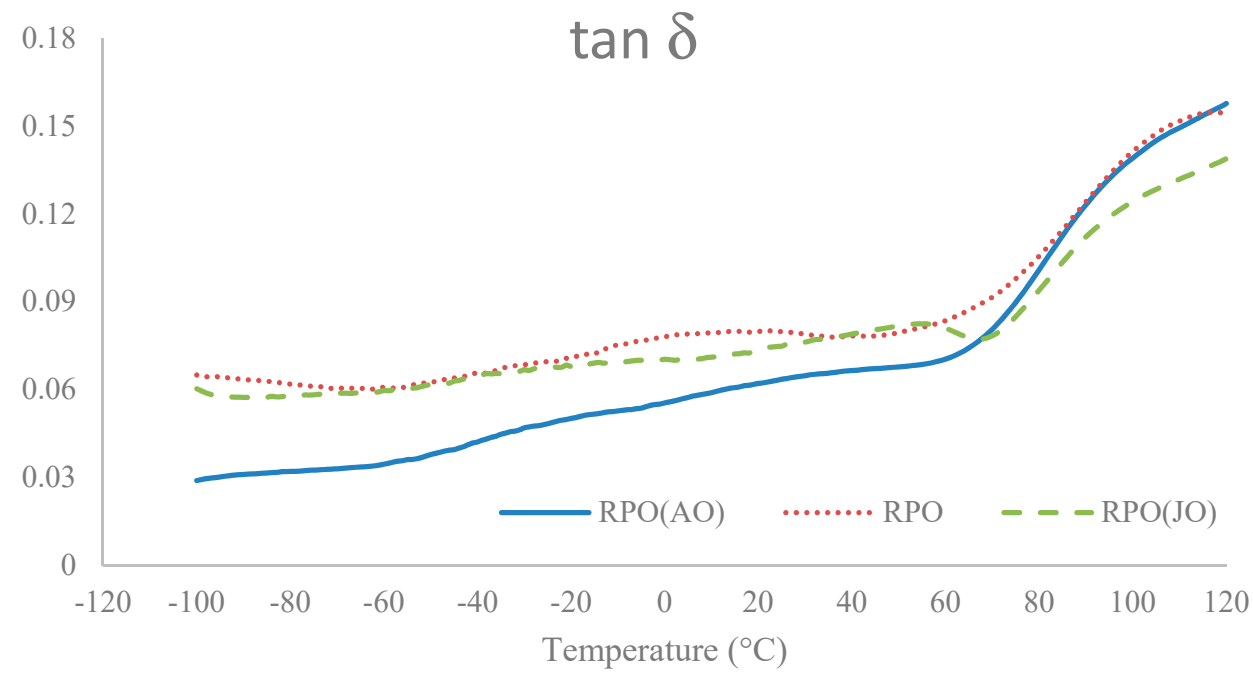

Figure 9. Variation of Tan d versus temperature for the different polymers. 
The delta modulus ( $\tan \delta$ ) has an inverse proportion with the $\mathrm{OH}$ number across the temperature range. Initially, the polymer developed with $\mathrm{RPO}(\mathrm{AO})$ showed the lowest tan $\delta$ value and that developed from RPO showed the highest. The lesser height of the delta peaks is associated with the crosslinking arising from the strong covalent bonds between the high functionality polyol and the hard segment component, which restrict the mobility of the dangling chains [50]. After the temperature of $67^{\circ} \mathrm{C}$ the tan $\delta$ of the polymer from $\mathrm{RPO}(\mathrm{AO})$ increased significantly while the polymer from $\mathrm{RPO}(\mathrm{JO})$ displayed the lowest values. The restriction in the molecular mobility of the RPO(JO) due to stronger urethane linkages in the network under stress might increase the wear resistance of the PU. Hence, $\mathrm{RPO}(\mathrm{JO})$ can provide a better PU for coating application when compared to RPO and $\mathrm{RPO}(\mathrm{AO})$ [48].

\section{Conclusions}

Polyester polyols and polyurethane were prepared from recovered palm oil, recovered palm oil with $10 \%$ jatropha oil, and recovered palm oil with $10 \%$ algae oil as additive. The polymerizations were conducted via one pot epoxidation and hydrolysis followed by isocyanation of the hydroxyl groups $(-\mathrm{OH})$. The characterization of the oils, epoxidized oil and polyols was conducted and the results were compared among the different samples. Residual palm oil has a much lower IV number than that of refined palm oil but a higher FFA content. Algae oil, on the other hand, has a slightly higher IV value than jatropha, but it contains predominantly C20:5 fatty acid chain which is longer and with much higher double bonds than jatropha which is predominantly C18:1. Algae oil also contains much higher phospholipid content and the phosphate groups are found to be in the polyol and the final polyurethane. The addition of 10\% algae oil to RPO almost doubled the hydroxyl of value of the polyol compared to pure RPO polyol The thermal properties of the final polyurethanes were analyzed by different techniques and the results were compared. We found that the addition of polyunsaturated oil as additive into the highly saturated recovered palm oil significantly enhanced the thermal properties of the final polymer. Moreover, the polymer developed with algae oil as additive showed a higher thermal stability than that of jatropha oil due to the higher crosslinking from the polyunsaturated fatty acid chain and the inclusion of phosphate groups. Differential scanning calorimetry showed significant increment of $\mathrm{T}_{\mathrm{g}}$ for the hard segment and a lower $\mathrm{Tg}$ for the soft segments of the polyurethanes produced with $\mathrm{RPO}(\mathrm{AO})$. Finally, the usage of, non-edible, biodegradable and renewable recovered palm oil with jatropha oil and algae oil as additive has a high potential for the production of environmentally friendly bio-based polyurethanes.

Author Contributions: Conceptualization, R.Z. and J.C.G.; methodology, R.Z., J.C.G. and M.M.A.; software, J.C.G.; validation, R.Z. and M.M.A.; formal analysis, J.C.G. and R.Z.; investigation, J.C.G.; resources, R.Z. and M.M.A.; data curation, J.C.G.; writing-original draft preparation, J.C.G. and R.Z.; writing-review and editing, R.Z., R.Y. and M.N.M.; visualization, J.C.G.; supervision, R.Z., M.M.A., M.N.M. and R.Y.; project administration, R.Z. and J.C.G.; funding acquisition, R.Z. and R.Y. All authors have read and agreed to the published version of the manuscript.

Funding: This research was funded by University Putra Malaysia through grant GP-IPS/2016/9503300.

Institutional Review Board Statement: Not applicable.

Informed Consent Statement: Not applicable.

Data Availability Statement: The data presented in this study are available on request from the corresponding author.

Acknowledgments: Appreciation is given to all assistant engineers in the department of process and food engineering for their guidance and laboratory assistance.

Conflicts of Interest: The authors declare no conflict of interest. 


\section{References}

1. Global Polyurethane Demand 2012-2024—Statista Website1. Available online: https://www.statista.com/statistics/747004 /polyurethane-demand-worldwide/ (accessed on 15 August 2021).

2. Petrović, Z.S. Polyurethanes from vegetable oils. Polym. Rev. 2008, 48, 109-155. [CrossRef]

3. Desroches, M.; Escouvois, M.; Auvergne, R.; Caillol, S.; Boutevin, B. From vegetable oils to polyurethanes: Synthetic routes to polyols and main industrial products. Polym. Rev. 2012, 52, 38-79. [CrossRef]

4. Zlatanić, A.; Lava, C.; Zhang, W.; Petrović, Z.S. Effect of structure on properties of polyols and polyurethanes based on different vegetable oils. J. Polym. Sci. Part B Polym. Phys. 2004, 42, 809-819. [CrossRef]

5. Caillol, S.; Desroches, M.; Boutevin, G.; Loubat, C.; Auvergne, R.; Boutevin, B. Synthesis of new polyester polyols from epoxidized vegetable oils and biobased acids. Eur. J. Lipid Sci. Technol. 2012, 114, 1447-1459. [CrossRef]

6. Dinda, S.; Patwardhan, A.V.; Goud, V.V.; Pradhan, N.C. Epoxidation of cottonseed oil by aqueous hydrogen peroxide catalysed by liquid inorganic acids. Bioresour. Technol. 2008, 99, 3737-3744. [CrossRef] [PubMed]

7. Beneš, H.; Vlček, T.; Černá, R.; Hromádková, J.; Walterová, Z.; Svitáková, R. Polyurethanes with bio-based and recycled components. Eur. J. Lipid Sci. Technol. 2012, 114, 71-83. [CrossRef]

8. Badri, K.H.; Ahmad, S.H.; Zakaria, S. The production of a high-functionality RBD palm kernel-based polyester polyol. J. Appl. Polym. Sci. 2001, 82, 827-832. [CrossRef]

9. MPOB. Economics, and Industry Division. MPOB Website. Available online: http://bepi.mpob.gov.my/index.php/statistics/ production/71-production-2012/298-production-of-crude-oil-palm-2012.html (accessed on 10 October 2013).

10. Chavarro-Gomez, J.; Mokhtar, M.N.; Sulaiman, A.; Samsu Baharuddin, A.; Busu, Z.A. Recovery of Residual Crude Palm Oil from the Empty Fruit Bunch Spikelets Using Environmentally Friendly Processes. Sep. Sci. Technol. 2015, 50, 1677-1683. [CrossRef]

11. Gomez, J.C.; Mokhtar, M.N.; Sulaiman, A.; Zakaria, R.; Baharuddin, A.S.; Busu, Z. Study on Residual Oil Recovery from Empty Fruit Bunch by Combination of Water and Steam Process. J. Food Process. Eng. 2015, 38, 385-394. [CrossRef]

12. Malaysian Palm Oil Council Website. Available online: http://mpoc.org.my/malaysian-palm-oil-sector-performance-in-2020 -and-market-opportunities / (accessed on 15 August 2021).

13. Cardeño, F.; Rios, L.A.; Cardona, J.F.; Ocampo, D. Síntesis de Resinas Alquídicas a partir de Aceites de Higuerilla, de Palma y de Fritura, Mezclados con Aceite de Soja. Inf. Tecnológica 2013, 24, 33-42. [CrossRef]

14. Polaczek, K.; Kurańska, M.; Auguścik-Królikowska, M.; Prociak, A.; Ryszkowska, J. Open-cell polyurethane foams of very low density modified with various palm oil-based bio-polyols in accordance with cleaner production. J. Clean. Prod. 2021, $290,125875$. [CrossRef]

15. Prociak, A.; Malewska, E.; Kurańska, M.; Bak, S.; Budny, P. Flexible polyurethane foams synthesized with palm oil-based bio-polyols obtained with the use of different oxirane ring opener. Ind. Crop. Prod. 2018, 115, 69-77. [CrossRef]

16. Arniza, M.Z.; Hoong, S.S.; Idris, Z.; Din, A.K.; Choo, Y.M. Synthesis of transesterified palm olein-based Polyol and rigid polyurethanes from this polyol. J. Am. Oil Chem. Society 2015, 92, 243-255. [CrossRef] [PubMed]

17. Ng, W.S.; Lee, C.S.; Chuah, C.H.; Cheng, S.-F. Preparation and modification of water-blown porous biodegradable polyurethane foams with palm oil-based polyester polyol. Ind. Crop. Prod. 2017, 97, 65-78. [CrossRef]

18. Tanaka, R.; Hirose, S.; Hatakeyama, H. Preparation and characterization of polyurethane foams using a palm oil-based polyol. Bioresour. Technol. 2008, 99, 3810-3816. [CrossRef] [PubMed]

19. Aung, M.M.; Yaakob, Z.; Kamarudin, S.; Abdullah, L.C. Synthesis and characterization of Jatropha (Jatropha curcas L.) oil-based polyurethane wood adhesive. Ind. Crop. Prod. 2014, 60, 177-185. [CrossRef]

20. Pawar, M.S.; Kadam, A.S.; Dawane, B.S.; Yemul, O.S. Synthesis and characterization of rigid polyurethane foams from algae oil using biobased chain extenders. Polym. Bull. 2016, 73, 727-741. [CrossRef]

21. Williams, P.J.L.B.; Laurens, L.M. Microalgae as biodiesel \& biomass feedstocks: Review \& analysis of the biochemistry, energetics \& economics. Energy Environ. Sci. 2010, 3, 554-590.

22. Mülhaupt, R. Green Polymer Chemistry and Bio-based Plastics: Dreams and Reality. Macromol. Chem. Phys. 2013, 214, 159-174. [CrossRef]

23. D'Alessandro, D.M.; Smit, B.; Long, J.R. Carbon dioxide capture: Prospects for new materials. Angew. Chem. Int. Ed. 2010, 49, 6058-6082. [CrossRef]

24. Roesle, P.; Stempfle, F.; Hess, S.K.; Zimmerer, J.; Río Bártulos, C.; Lepetit, B.; Eckert, A.; Kroth, P.G.; Mecking, S. Synthetic polyester from algae oil. Angew. Chem. Int. Ed. 2014, 53, 6800-6804. [CrossRef]

25. Hazmi, A.S.A.; Aung, M.M.; Abdullah, L.C.; Salleh, M.Z.; Mahmood, M.H. Producing Jatropha oil-based polyol via epoxidation and ring opening. Ind. Crop. Prod. 2013, 50, 563-567. [CrossRef]

26. MPOB. МРОB Test Method p2.5:2004, Method of Test for Palm Oil and Palm Oil Products: Determination of Acidity; Malaysian Palm Oil Board: Selangor, Malaysia, 2004.

27. Goh, S.H.; Tong, S.L.; Gee, P.T. Inorganic phosphate in crude palm oil: Quantitative analysis and correlations with oil quality parameters. J. Am. Oil Chem. Soc. 1984, 61, 1601-1604. [CrossRef]

28. Vaskovsky, V.E.; Kostetsky, E.Y.; Vasendin, I.M. A universal reagent for phospholipid analysis. J. Chromatogr. A 1975, $114,129-141$. [CrossRef]

29. American Oil Chemists' Society. Method Ce 2-66, Preparation of Methyl ester of Fatty Acids, 5th ed.; Fireston, D., Ed.; Official Methods and Recommended Practices of the American Oil Chemists' Society; AOCS Press: Urbana, IL, USA, 1998. 
30. American Oil Chemists' Society. Method Ce 1-62, Fatty Acid Composition by Gas Chromatography, 5th ed.; Fireston, D., Ed.; Official Methods and Recommended Practices of the American Oil Chemists' Society; AOCS Press: Urbana, IL, USA, 1998.

31. MPOB Official Palm Oil Source. MPOB Website. Available online: http:/ / www.palmoilworld.org (accessed on 15 August 2021).

32. Petrović, Z.S.; Wan, X.; Bilić, O.; Milić, J.; Degruson, D. Polyols and polyurethanes from crude algal oil. J. Am. Oil Chem. Soc. 2013, 90, 1073-1078. [CrossRef]

33. Peyrton, J.; Chambaretaud, C.; Sarbu, A.; Avérous, L. Biobased Polyurethane Foams Based on New Polyol Architectures from Microalgae Oil. ACS Sustain. Chem. Eng. 2020, 8, 12187-12196. [CrossRef]

34. Gurr, M.I.; Brawn, P. The biosynthesis of polyunsaturated fatty acids by photosynthetic tissue. Eur. J. Biochem. 1970, 17, 19-22. [CrossRef]

35. Lewis, A.L. Phosphorylcholine-based polymers and their use in the prevention of biofouling. Colloids Surf. B Biointerf. 2000, 18, 261-275. [CrossRef]

36. Nichols, B.W. Light induced changes in the lipids of Chlorella vulgaris. Biochim. Et Biophys. Acta (BBA)-Lipids Lipid Metab. 1965, 106, 274-279. [CrossRef]

37. Rao, K.S.; Chakrabarti, P.P.; Rao, B.V.S.K.; Prasad, R.B.N. Phospholipid composition of Jatropha curcus seed lipids. J. Am. Oil Chem. Soc. 2009, 86, 197-200. [CrossRef]

38. Gunstone, F.D. The chemistry of oils and fats. In Sources, Composition, Properties and Uses; Blackwell Publishing Ltd.: Hoboken, NJ, USA, 2004; 345p.

39. Hatzakis, E.; Koidis, A.; Boskou, D.; Dais, P. Determination of phospholipids in olive oil by 31P NMR spectroscopy. J. Agric. Food Chem. 2008, 56, 6232-6240. [CrossRef]

40. Pawlik, H.; Prociak, A. Influence of palm oil-based polyol on the properties of flexible polyurethane foams. J. Polym. Environ. 2012, 20, 438-445. [CrossRef]

41. Saifuddin, N.; Chun, W.O.; Wei, Z.L.; Xin, N.K. Palm Oil Based Polyols for Polyurethane Foams Application. In Proceedings of the UNITEN-IKRAM, Selangor, Malaysia, 26 June 2010.

42. Velencoso, M.M.; Ramos, M.J.; Klein, R.; De Lucas, A.; Rodriguez, J.F. Thermal degradation and fire behaviour of novel polyurethanes based on phosphate polyols. Polym. Degrad. Stab. 2014, 101, 40-51. [CrossRef]

43. Zhang, M.; Zhang, L.; Hu, L.; Zhou, Y. Synthesis of rigid polyurethane foams with castor oil-based flame retardant polyols. Ind. Crop. Prod. 2014, 52, 380-388. [CrossRef]

44. Galià, M.; de Espinosa, L.M.; Ronda, J.C.; Lligadas, G.; Cádiz, V. Vegetable oil-based thermosetting polymers. Eur. J. Lipid Sci. Technol. 2010, 112, 87-96. [CrossRef]

45. Chen, R.; Zhang, C.; Kessler, M.R. Polyols and polyurethanes prepared from epoxidized soybean oil ring-opened by polyhydroxy fatty acids with varying OH numbers. J. Appl. Polym. Sci. 2015, 132, 41213. [CrossRef]

46. Mustafa, S.; Gan, S.N.; Yahya, R. Synthesis and Characterization of Novel Alkyds Derived from Palm Oil Based Polyester Resin. Asian J. Chem. 2013, 25, 8737-8740. [CrossRef]

47. Wu, L.; Van Gemert, J.; Camargo, R.E. Rheology Study in Polyurethane Rigid Foams. Huntsman International Technical Presentations Web Site. Available online: http://www.huntsman.com/polyurethanes/a/Products/Technical\%20presentations\% 20overview (accessed on 10 October 2014).

48. Saalah, S. Synthesis and Characterization of Jatropha Oil-Based Waterborne Polyurethane Dispersions. Ph.D. Thesis, University Putra Malaysia, Serdang, Malaysia, 2016.

49. Guo, A.; Javni, I.; Petrovic, Z. Rigid Polyurethane Foams Based on Soybean Oil. J. Appl. Polym. Sci. 2000, 77, 467-473. [CrossRef]

50. Saba, N.; Jawaid, M.; Alothman, O.Y.; Paridah, M.T. A review on dynamic mechanical properties of natural fibre reinforced polymer composites. Constr. Build. Mater. 2016, 106, 149-159. [CrossRef] 